\title{
Cervical Epidural Abscess: Rare Complication of Bacterial Endocarditis with Streptococcus Viridans: A Case Report
}

\author{
Jae-Sang Oh, Jai-Joon Shim, Kyeong-Seok Lee, Jae-Won Doh \\ Department of Neurosurgery, Soonchunhyang University Cheonan Hospital, Soonchunhyang University \\ College of Medicine, Cheonan, Korea
}

Although many patients with infective endocarditis (IE) complain of joint, muscle, and back pain, infections at these sights are rare. The incidence of spinal abscess in cervical spine complicating endocarditis is very rare. Although the surgical management is the mainstay of treatment, conservative treatment can get success in selected patients. We report a patient with cervical epidural abscess due to Streptococcus viridans endocarditis. Both epidural abscess and IE were managed conservatively with intravenous antibiotics for 8 weeks, with recovery. It is important to remind spinal epidural abscess can occur in those patients with bacterial endocarditis.

Key Words: Spondylitis $\cdot$ Abscess $\cdot$ Endocarditis $\cdot$ Streptococcus viridans

\section{INTRODUCTION}

Spinal epidural abscess is a surgical emergency that requires immediate decompression ${ }^{7}$. The common causes of epidural abscess are surgical interventions in the spinal canal and spread from nearby bone or soft tissues ${ }^{2}$. Conservative management of epidural abscess is reserved for patients with poor surgical risk or patients without any neurological deficit ${ }^{2}$. The association between spinal epidural abscess and infective endocarditis (IE) has rarely been described ${ }^{3)}$. In fact, only eleven cases of vertebral osteomyelitis complicating streptococcus viridans endocarditis have been previously reported, and of these, only three were located in the cervical spine. The authors present a case of cervical epidural abscess associated with streptococcus viridans endocarditis.

\section{CASE REPORT}

A 44-year-old man was admitted with severe posterior neck

- Received: July 1, 2014 • Revised: October 5, 2014

- Accepted: October 8, 2014

Corresponding Author: Jae-Won Doh, MD, PhD

Department of Neurosurgery, Soonchunhyang University Cheonan

Hospital, 8 Soonchunhyang 2 Gil, Dongnam-gu, Cheonan-city,

Chungcheongnam-do 330-721, Korea

Tel: +82-41-570-2180/3651, Fax: +82-41-572-9297

E-mail: metatron1324@hotmail.com

®This is an Open Access article distributed under the terms of the Creative Commons Attribution Non-Commercial License (http://creativecommons.org/ licenses/by-nc/3.0/) which permits unrestricted non-commercial use, distribution, and reproduction in any medium, provided the original work is properly cited. pain radiating to both shoulder of 13 days duration, and which had aggravated 4 days before admission. His symptoms were further aggravated by a cervical epidural block. He had been transferred from other hospital. He developed high-grade fever on the day of hospitalization. On examination, he was febrile $\left(38^{\circ} \mathrm{C}\right)$, with a pulse rate of $110 / \mathrm{min}$ and blood pressure of 120/60 mmHg. Chest auscultation revealed coarse crepitations in the left infrascapular area. Neurological examination revealed no motor weakness or sensory loss. Investigations

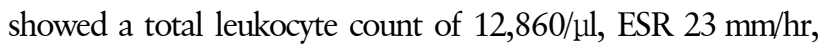
and CRP $24.96 \mathrm{mg} / \mathrm{dl}$. Renal and liver function tests were normal. Chest X-ray showed no active lesion in either lung or heart enlargement. He was already treated by the triple antibiotics (ceftriaxone, vancomycin, rifampin) before admission. But intravenous antibiotics were changed to ceftriaxone and gentamycin, because one initial blood culture grew Streptococcus viridans. The patient had a previous history of heart disease some 10 years before admission. Magnetic resonance imaging (MRI) of the cervical spine showed the highly enhanced epidural mass on C3-4 and no paraspinal abscess (Fig 1), and transesophageal echocardiography (TEE) depicted the small mobile vegetation on the tricuspid valve side, and an underlying subaortic ventricular septal defect (VSD) lesion (Fig 2). We planned the conservative treatment except in case of developing the neurologic deficit or increasing epidural abscess on follow-up MRI. And we decided to continue the intravenous antibiotics for 8 weeks when his pain improved within 2 weeks of admission. Follow-up MRI of the cervical region after four weeks of intravenous antibiotics treatment showed resolution of the epidural abscess, but newly developed discitis and osteomyelitis. And follow-up echocardio- 
Table 1. Clinical summary of vertebral osteomyelitis complicating infective endocarditis caused by streptococcus viridans

\begin{tabular}{|c|c|c|c|c|c|c|c|}
\hline No. & Author & Age/sex & Valve & Organism & Site of infection & Mode of therapy & Outcome \\
\hline 1 & Demers et al $^{11)}$ & $64 / \mathrm{M}$ & Aortic & Steptococcus sanguis & $\mathrm{L} 2, \mathrm{~L} 3, \mathrm{~L} 4$ & Conservative treatment & Died \\
\hline 2 & Allen et a $\left.\right|^{2)}$ & $57 / F$ & Aortic & Streptococcus bovis & $L 2, L 3$ & Conservative treatment & Survived \\
\hline 3 & Acar et al ${ }^{11}$ & NS & $u-k$ & Streptococcus viridans & $\mathrm{L} 5, \mathrm{~S} 1$ & $u-k$ & $u-k$ \\
\hline 4 & Acar et al ${ }^{1)}$ & NS & $u-k$ & Streptococcus viridans & $\mathrm{T7}, \mathrm{T} 8$ & $u-k$ & $u-k$ \\
\hline 5 & Elian et $\mathrm{al}^{12)}$ & $47 / M$ & Mitral & Streptococcus sanguis & L4, L5 & Surgery & Survived \\
\hline 6 & Morrey et $\mathrm{al}^{(6)}$ & $39 / F$ & Mitral & Streptococcus viridans & L5 & Conservative treatment & Survived \\
\hline 7 & Rhodes et $\mathrm{al}^{19)}$ & $35 / F$ & Mitral & Steptococcus sanguis & Lumbar & Conservative treatment & Sunvived \\
\hline 8 & Myles et al ${ }^{17)}$ & $60 / M$ & Mitral & Steptococcus sanguis & $\mathrm{C} 3, \mathrm{C} 4$ & Conservative treatment & Sunvived \\
\hline 9 & Lawrence et al $^{10)}$ & $78 / F$ & Aortic & Streptococcus bovis & $L 2, L 3$ & Conservative treatment & Died \\
\hline 10 & Lawrence et al ${ }^{10)}$ & $87 / F$ & Mitral & Streptococcus mitis & L2, L3 & Conservative treatment & Survived \\
\hline 11 & Choubrac et $\mathrm{al}^{8)}$ & $48 / \mathrm{M}$ & Mitral & Streptococcus mitis & $\mathrm{C} 5, \mathrm{C} 6$ & $u-k$ & Survived \\
\hline 12 & PC & $44 / \mathrm{M}$ & Tricuspid & Streptococcus viridans & C3, C4 & Conservative treatment & Sunvived \\
\hline
\end{tabular}

PC: present case, u-k: unknown
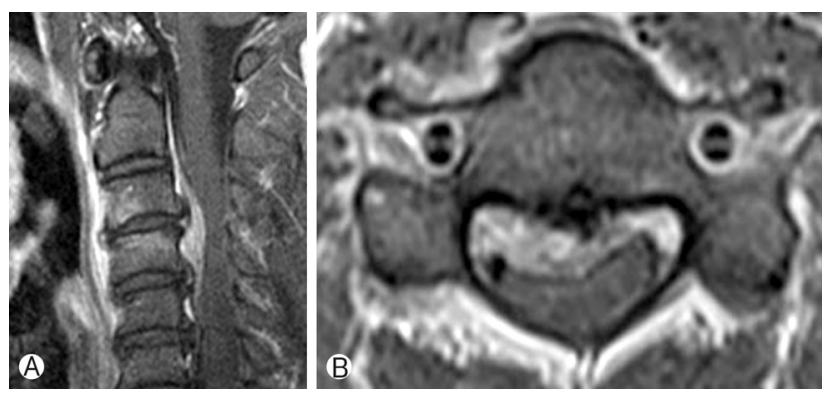

Fig. 1. (A) A T1-weighted sagittal MR image after intravenous gadolinium injection showing an epidural abscess located adjacent to the anterior aspect of spinal cord and extending from C3 to C4. (B) A T1-weighted axial MR image with enhancement showing marked compression of the anterior spinal cord at this site.
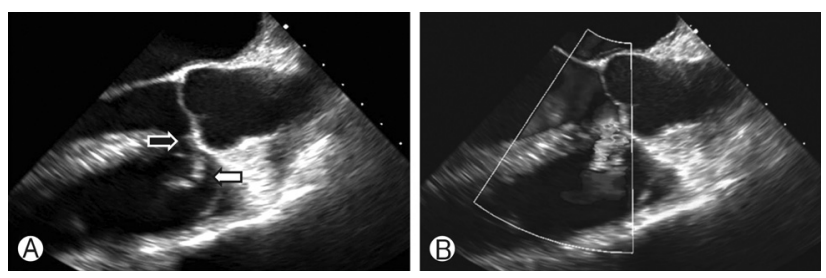

Fig. 2. (A) Transesophageal echocardiograph showing the underlying subaortic ventricular septal defect (black arrow) lesion and the small mobile vegetation on the tricuspid valve side (white arrow). (B) The Doppler image demonstrating shunt flow from the right to the left ventricle.

graphy at four weeks showed no change in the vegetation. MRI taken after four months of treatment revealed complete resolution of discitis and osteomyelitis (Fig 3). The patient was well at his 6-month follow-up, and symptoms almost completely subsided.

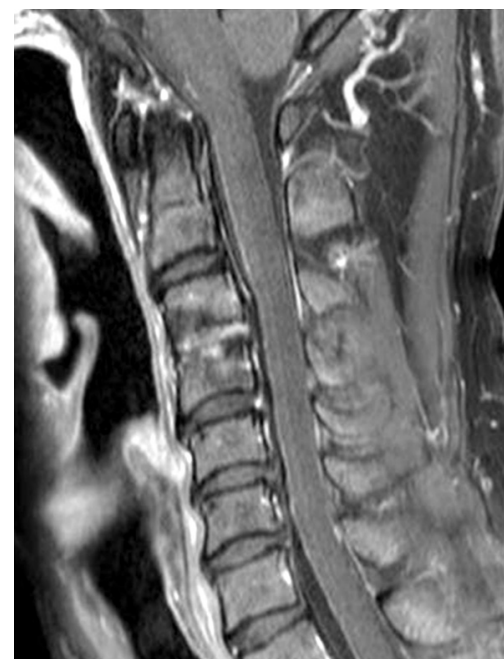

Fig. 3. Gadolinium-enhanced T1-weighted sagittal MR image of the lesion after 4 months of antibiotic therapy showing the cervical epidural abscess had significantly decreased in size. However, the presence of a hyperintense and contrast-enhanced disc space and vertebral body suggested discitis and osteomyelitis.

\section{DISCUSSION}

Spinal epidural abscess is a rare clinical condition with an estimated incidence of $0.2-1.2 / 10,000$ hospital admissions in the western world ${ }^{4)}$. Its usual causes are intervention in the spinal canal (lumbar puncture, any surgery), hematogenous spread from skin and soft tissues, direct extension of vertebral osteomyelitis, abdominal abscess, infection of the mediastinum, and rarely IE. In fact, 14-22\% of epidural abscess cases are associated with spine surgery or a percutaneous spine procedure ${ }^{18)}$. Blunt trauma possibly precedes symptoms of spinal 
epidural abscess in $15-35 \%$ of cases ${ }^{14)}$. The most common causative organism, Staphylococcus aureus, is present in up to $70 \%$ of all spinal epidural abscesses, and is followed by Streptococcus species, which account for approximately 7\% of spinal abscesses ${ }^{18)}$. Mycobacterium tuberculosis, fungal species, and parasitic organisms are exceptionally rare causes of spinal epidural abscess.

In the present case, although he had been treated by acupuncture and epidural block, we thought the origin of the cervical epidural abscess was not iatrogenic, but rather IE, because his symptom started before these treatments. In addition, the patient already had an underlying subaortic VSD.

The initial result of blood culture on our case was Streptococci viridans. The three most common organisms responsible for IE are Streptococci viridans, Staphylococcus aureus, and Coagulase negative Staphylococci ${ }^{22)}$. Streptococci viridans is the most common causative organism and accounts for 50\% of IE cases.

As was observed in our case, cervical abscess could be originate from embolic involvement of aortic valve endocarditis by hematogenous spread ${ }^{3)}$. However, IE can develop without a valve anomaly. Bayer et al..$^{5}$ reported that, $18 \%$ of septicemia patients without a cardiac anomaly may have echocardiographic evidence of endocarditis.

A MEDLINE search of IE revealed an incidence of vertebral osteomyelitis of $6.5 \%$ among 1,099 IE patients ${ }^{6,9,11,21)}$. Although Streptococcus viridans is the most common causative organism, Staphylococcus aureus is the most common organism to cause vertebral osteomyelitis subsequent to IE. In a literature review, in $11(23 \%)$ of 48 patients with vertebral osteomyelitis due to endocarditis Streptococcus viridans was identified as the causative organism. The viridans group stretocococci involved the 6 major groups: the S. mutans group, S. salivarius groups, S. anginosus group, S. mitis group, S. sanguinis group and S. bovis group ${ }^{13)}$. Table 1 summarizes the 12 reported cases of Streptococcus viridans endocarditis with vertebral osteomyelitis, including one present case (Table 1). However, vertebral osteomyelitis has only been previously reported in 3 cases $(25 \%)$ in the cervical spine.

The treatment of spinal epidural abscess usually consists of decompressive laminectomy and debridement with antibiotics $^{20)}$. However, many cases have been managed conservatively ${ }^{15}$. Conservative management is reserved for poor risk patients with concomitant medical problems, patients with an extensive epidural abscess (from the cervical to lumbar region), patients with complete paralysis lasting for more than three days, and patients with no neurological deficit ${ }^{7}$. In our case, conservative management was adopted because he was neurologically intact. As is shown by Table 1 , the majority of patients with a spinal abscess caused by Streptococcus viridans endocar- ditis improved after conservative treatment (Table 1).

In our opinion, spinal epidural abscess with Streptococcus viridans endocarditis is usually benign course. So if the culture proven Streptococcus viridans or patients have the history of cardiac valve anomay, generally IE should be confirmed by echocardiography and epidural abscess could be cured by conservative treatment.

\section{CONCLUSION}

Spinal epidural abscess rarely accompanies IE. When encountered Streptococci viridans is the most common causative organism, and accounts for 50\% of IE cases. It is important to be aware of the possibility of a spinal epidural abscess accompanying Streptococci viridans endocarditis. But in general, it could be treated by the conservative treatment. Conservative treatment is a good first line treatment in selected patients.

\section{REFERENCES}

1. Acar JF: A propos de deux cas de spondylodiscite revelatrice d'unedocardites a Streptococcus viridians. Gaz Med France 81: 2351, 1974

2. Allen M, Flannery A, Fisher J: Spinal epidural and subdural abscesses In: Textbook of neurosurgery. Wilkins RH, Rengachary SS (eds.) 2nd Ed. McGraw Hill. USA: 3327-3331, 1996

3. Arnáiz-García ME, González-Santos JM, López-Rodriguez J, Dalmau-Sorli MJ, Bueno-Codoñer M, Arévalo-Abascal A: Intramedullary cervical abscess in the setting of aortic valve endocarditis. Asian Cardiovascular and Thoracic Annals, 2013

4. Baker AS, Ojemann RG, Swartz MN, Richardson EP, Jr.: Spinal epidural abscess. The New England journal of medicine 293: 463-468, 1975

5. Bayer AS, Lam K, Ginzton L, Norman DC, Chiu CY, Ward JI: Staphylococcus aureus bacteremia. Clinical, serologic, and echocardiographic findings in patients with and without endocarditis. Archives of internal medicine 147:457-462, 1987

6. Caputo GM, Archer GL, Calderwood SB, DiNubile MJ, Karchmer AW: Native valve endocarditis due to coagulasenegative staphylococci. Clinical and microbiologic features. The American journal of medicine 83:619-625, 1987

7. Carey M: Infections of the spine and spinal cord. In: Neurological surgery: 4th ed. Youmans JR (ed.) Philadelphia Saunder: 270-3304, 1996

8. Choubrac P, Mathe G, Haas CH, Crickx B, Robin PM, Dyan $\mathrm{A}$, et al: [Spondylodiscitis revealing bacterial endocarditis]. Annales de medecine interne 127:117-121, 1976

9. Churchill MA, Jr., Geraci JE, Hunder GG: Musculoskeletal manifestations of bacterial endocarditis. Annals of internal medicine 87:754-759, 1977

10. Cone LA, Hirschberg J, Lopez C, Kanna PK, Goldstein EJ, Kazi A, et al: Infective endocarditis associated with spondylodiscitis and frequent secondary epidural abscess. Surgical neurology 69: 
121-125, 2008

11. Demers C, Tremblay M, Lacourciere Y: Acute vertebral osteomyelitis complicating Streptococcus sanguis endocarditis. Annals of the rheumatic diseases 47:333-336, 1988

12. Elian D, Hassin D, Tomer A, Bank H, Eisenstein Z: Spinal epidural abscess: an unusual complication of bacterial endocarditis. Infection 12:258-259, 1984

13. Facklam R: What happened to the streptococci: overview of taxonomic and nomenclature changes. Clinical microbiology reviews 15:613-630, 2002

14. Mackenzie AR, Laing RB, Smith CC, Kaar GF, Smith FW: Spinal epidural abscess: the importance of early diagnosis and treatment. Journal of neurology, neurosurgery, and psychiatry 65 : 209-212, 1998

15. Mampalam TJ, Rosegay H, Andrews BT, Rosenblum ML, Pitts LH: Nonoperative treatment of spinal epidural infections. Journal of neurosurgery 71:208-210, 1989

16. Morrey BF, Kelly PJ, Nichols DR: Viridans streptococcal osteo- myelitis of the spine. Case report with five-year follow-up. The Journal of Bone and joint surgery American volume 62:10091010, 1980

17. Myles PS: Septic discitis as a presentation of endocarditis. The Medical journal of Australia 146:656-657, 1987

18. Reihsaus E, Waldbaur H, Seeling W: Spinal epidural abscess: a meta-analysis of 915 patients. Neurosurgical review 23:175204; discussion 205, 2000

19. Rhodes LE, Haboubi N: Infective endocarditis presenting with back pain and stroke. The Journal of infection 12:184-185, 1986

20. Sampath P, Rigamonti D: Spinal epidural abscess: a review of epidemiology, diagnosis, and treatment. Journal of spinal disorders 12:89-93, 1999

21. Thomas P, Allal J, Bontoux D, Rossi F, Poupet JY, Petitalot JP, et al: Rheumatological manifestations of infective endocarditis. Annals of the rheumatic diseases 43:716-720, 1984

22. Ytterberg SR: Viral arthritis. Current opinion in rheumatology 11:275-280, 1999 